\title{
Evaluation of different types of enamel conditioning before application of a fissure sealant
}

\author{
Philip Ciucchi • Klaus W. Neuhaus • Marta Emerich • \\ Anne Peutzfeldt • Adrian Lussi
}

Received: 25 September 2011 /Accepted: 18 April 2013 /Published online: 1 May 2013

(C) Springer-Verlag London 2013

\begin{abstract}
The aim of the study was to compare fissure sealant quality after mechanical conditioning of erbiumdoped yttrium aluminium garnet (Er:YAG) laser or air abrasion prior to chemical conditioning of phosphoric acid etching or of a self-etch adhesive. Twenty-five permanent molars were initially divided into three groups: control group $(n=5)$, phosphoric acid etching; test group 1 $(n=10)$, air abrasion; and test group 2, $(n=10)$ Er:YAG laser. After mechanical conditioning, the test group teeth were sectioned buccolingually and the occlusal surface of one half tooth (equal to one sample) was acid etched, while a self-etch adhesive was applied on the other half. The fissure system of each sample was sealed, thermo-cycled and immersed in $5 \%$ methylene dye for $24 \mathrm{~h}$. Each sample was sectioned buccolingually, and one slice was analysed microscopically. Using specialized software microleakage, unfilled margin, sealant failure and unfilled area proportions were calculated. A nonparametric ANOVA model was applied to compare the Er:YAG treatment with that of air abrasion and the self-etch adhesive with phosphoric acid $(\alpha=0.05)$. Test groups were compared to the control group using Wilcoxon rank sum tests $(\alpha=0.05)$. The control group displayed significantly lower microleakage but higher unfilled area proportions than the Er:YAG laser + self-etch adhesive group and displayed significantly higher unfilled margin and unfilled area proportions than the air-
\end{abstract}

P. Ciucchi $(\bowtie) \cdot$ K. W. Neuhaus $\cdot$ A. Peutzfeldt $\cdot$ A. Lussi Department of Operative, Preventive and Paediatric Dentistry, School of Dental Medicine, University of Bern, Freiburgstrasse 7, 3010 Bern, Switzerland

e-mail: philip.ciucchi@gmail.com

\section{Emerich}

Department of Maxillofacial Surgery and Dental Surgery,

Medical University of Gdansk, Al. Zwycięstwa 41/42,

80-210 Gdańsk, Poland abrasion + self-etch adhesive group. There was no statistically significant difference in the quality of sealants applied in fissures treated with either Er:YAG laser or air abrasion prior to phosphoric acid etching, nor in the quality of sealants applied in fissures treated with either self-etch adhesive or phosphoric acid following Er:YAG or air-abrasion treatment.

Keywords Fissure sealants · Air abrasion · Er:YAG laser . Self-etch adhesive $\cdot$ Phosphoric acid

\section{Introduction}

In recent years, there has been a decline in the prevalence of dental caries [1]. This can be correlated not only to the improved general awareness of oral hygiene but also to the increased use of fluoride. According to Attrill and Ashley, the localisation and distribution of caries across the tooth surface has also changed [2]. Gooch et al. state that caries on smooth surfaces have been reduced, whereas pit and fissure caries now account for $90 \%$ of caries-affected tooth surfaces [3]. It has been recently asserted that, in adolescents, occlusal surfaces of molars are the most carious-prone sites [4].

Caries develop more readily in pits and fissures on occlusal surfaces than on smooth surfaces due to promotion of plaque stagnation caused by tooth morphology [5]. The tooth morphology hinders self-cleaning occasioned by the moving food bolus, tongue, lips and cheeks. Furthermore, correct oral hygiene is more difficult to obtain in these areas [4]. In some cases, due to the increased use of fluoride, occlusal caries may progress underneath enamel that seems to be intact as judged by naked eyes [6, 7]. These so-called hidden occlusal caries are more difficult to diagnose with conventional radiographic methods than with histological 
preparation and staining [8]. In such sites, sealants may be applied preventively to serve as a mechanical barrier against the accumulation and maturation of plaque and, consequently, against the formation of dental caries [9].

For a sealant to be effective, it has to bond firmly to the tooth surface so that no microorganisms are able to penetrate the enamel-sealant interface. This requires effective pretreatment, most often sought through acid etching of the tooth surface. Unfortunately, conditions are not always optimal, and organic remnants as well as fissure morphology and aprismatic enamel structure can reduce etching performance and thus compromise adhesion [10]. It has been found that the most common cause for sealant failure is moisture contamination during placement [9]. However, with new etching techniques and the use of bonding agents, sealant adhesion can be increased [11]. The introduction of self-etch adhesives has reduced working time as they simultaneously demineralise and penetrate into enamel [12]. This approach is particularly useful in paediatric dentistry where reduced chair time increases patient acceptance. However, self-etch adhesives are believed to be less effective than phosphoric acid etching on intact enamel [13].

In recent years, novel instruments for caries removal have been developed, some of them also offering an enamel conditioning option intended as an alternative to traditional acid etching. The erbium-doped yttrium aluminium garnet (Er:YAG) laser has many applications in modern dentistry, ranging from cavity preparation and enamel conditioning to hypersensitivity treatment [14]. The Er:YAG laser is used in dentistry because it emits electromagnetic waves in the midinfrared region $(2.94 \mu \mathrm{m})$ that falls in an area of spectrum with high absorption peaks in water. The Er:YAG laser creates cavities by thermo-mechanical ablation. Despite the low water content of enamel ( $2-4 \%$ by weight), the rapid heating and sudden vaporisation of the water bound in the tissue causes expansion and micro-explosions, resulting in the ejection of particles of hard tissue [15]. The bactericidal effect of laser irradiation of pits and fissure could open a new perspective for this preventive treatment [14]. Another method of excavation is air abrasion. Air abrasion can be used as an alternative to bur excavation due to its selectiveness and high patient acceptance [16] and has also been suggested as an alternative for acid etching. Air abrasion consists of striking the tooth with abrasive particles at high air pressure. The most common abrasive powder for cutting tooth structure is alumina $\left(\mathrm{Al}_{2} \mathrm{O}_{3}\right)$, but caries-selective powders are now emerging [17]. Blasting the tooth structure causes removal of tooth structure and produces cavities or surface roughening depending on the energy applied. Air abrasion is often used for cleaning of the fissure system in order to enhance the diagnosis of caries. However, in this case, sodium bicarbonate $\left(\mathrm{NaHCO}_{3}\right)$ is used instead of alu$\operatorname{mina}\left(\mathrm{Al}_{2} \mathrm{O}_{3}\right)$ [18].
The aim of this in vitro study was (1) to compare Er:YAG laser or air-abrasion mechanical conditioning prior to phosphoric acid etching on fissure sealant quality and (2) to compare the chemical conditioning of a selfetch adhesive with that of phosphoric acid etching following either Er:YAG or air-abrasion treatment on fissure sealant quality.

\section{Materials and methods}

Twenty-five permanent molars free of occlusal caries were selected from a pool of extracted molars (no water fluoridation) stored in $1 \%$ chloramine solution. All cervical soft tissues were removed with a scalar (LM Dental, Parainen, Finland), and any plaque on occlusal surfaces was removed with a toothbrush (Trisa ultra-super-sensitive, Trisa AG, Triengen, Switzerland) and water. The fissure system in each tooth was checked with a diagnostic laser (DIAGNOdent, KaVo, Biberach, Germany) in order to make sure that no caries were present. All the teeth were kept in a $\mathrm{pH}$ neutral solution [19] when not experimented on. Every tooth was then embedded in a self-curing resin block (Paladur, Heraeus Kulzer, Hanau, Germany) with the crown remaining exposed. The occlusal surface was cleaned with a prophylaxis paste (Prophy-paste, 3M ESPE, St. Paul, MN, USA) for $5 \mathrm{~s}$ and thoroughly rinsed for $10 \mathrm{~s}$. The teeth were randomly divided into one control group and two test groups according to the surface conditioning applied:

- Control group $(n=5)$ : acid etching only-air drying for $5 \mathrm{~s}$, application of $35 \%$ ortho-phosphoric acid gel (Scotchbond, 3M ESPE, St. Paul, MN, USA) for $45 \mathrm{~s}$ and thorough rinsing for $20 \mathrm{~s}$ with an air-water syringe. - Test group $1(n=10)$ : air abrasion (Air Flow Prep K1 Max, EMS, Nyon, Switzerland)—alumina abrasion $\left(\mathrm{Al}_{2} \mathrm{O}_{3}\right), 5 \mathrm{bar}, 3 \mathrm{~g} / \mathrm{min}$ powder flow rate, $100 \mathrm{~mL} / \mathrm{min}$ water flow rate, $36 \mu \mathrm{m}$ average grain size, $2-3-\mathrm{mm}$ distance, $45^{\circ}-70^{\circ}$ angle.

- Test group $2(n=10)$ : Er:YAG laser (LiteTouch, Orcos Medical, Küsnacht, Switzerland) — enamel etch mode: $100 \mathrm{~mJ}, 35 \mathrm{~Hz}, 5 \mathrm{~W}, 140 \mu \mathrm{s}, 7.5 \mathrm{~J} / \mathrm{cm}^{2}$, max water cooled, 1.3-mm tip, 2-3-mm distance, $70^{\circ}-90^{\circ}$ angle.

After surface conditioning, the teeth in test groups 1 and 2 were then sectioned buccolingually through the fissure system with a diamond disc (Isomet 11-1180 low-speed saw, Buehler Ltd., IL, USA; $101.67 \mathrm{~mm}$ in diameter, $0.3 \mathrm{~mm}$ in thickness) in order to get two halves: A $(n=10)$ and $\mathrm{B}(n=10)$. The pulp was removed with a scalar (LM Dental) and the pulp chamber filled with melted utility wax. The occlusal surface of one of the halves (A) was air-dried for $5 \mathrm{~s}$, whereupon $35 \%$ ortho-phosphoric acid gel $\left(\mathrm{H}_{3} \mathrm{PO}_{4}\right.$; 
Scotchbond) was applied for $45 \mathrm{~s}$ and thoroughly rinsed for $20 \mathrm{~s}$. On the other half (B), the occlusal surface was dried for $5 \mathrm{~s}$, whereupon a self-etch adhesive (Adper Easy Bond, 3M ESPE, St. Paul, MN, USA) was applied for $20 \mathrm{~s}$ and then blown gently to distribute it across the surface. Finally, the adhesive was light-cured for $10 \mathrm{~s}$ (Bluephase, Ivoclar Vivadent, Schaan, Liechtenstein) at a power density of $1,200 \mathrm{~mW} / \mathrm{cm}^{2}$.

The fissure system of each sample of the three groups $(n=45)$ was then sealed (Clinpro, 3M ESPE, St. Paul, $\mathrm{MN}$, USA). The fissures were air-dried for $5 \mathrm{~s}$ before application of the sealant on the entire fissure system. Excess sealant and bubbles were removed with a brush. Each sealant was light-cured for $20 \mathrm{~s}$ (Bluephase). Once all the surfaces were sealed, the teeth were placed in a thermo-cycling machine for 4,000 cycles $\left(5^{\circ}-55^{\circ}\right)$ with a dwell time of $30 \mathrm{~s}$. Subsequently, the sectioned surface of each half sample was coated with a layer of transparent nail varnish. All tooth surfaces were then coated with melted utility wax followed by an additional layer of nail varnish, leaving the sealant and approximately $1.5 \mathrm{~mm}$ around the sealant uncovered. The teeth were immersed in a $5 \%$ methylene blue aqueous solution (Inselspital Apotheke, Bern, Switzerland) at room temperature for $24 \mathrm{~h}$ to allow dye penetration into possible gaps at the tooth-sealant interface. Using a low-speed diamond saw (Isomet), each sample was sectioned buccolingually with parallel cuts of $1 \mathrm{~mm}$ width yielding two slices. Because the sealant was applied on teeth that had been halved and because the sealant could have spread on the cut surfaces, the cuts were placed at a depth of $0.5 \mathrm{~mm}$ from the edge of each sample. The $0.5 \mathrm{~mm}$ slice was discarded (Fig. 1). If initial caries were revealed at the bottom of a fissure after sectioning, the slice was discarded and the tooth was replaced. The fissures were classified into shallow and deep fissures (Fig. 2a).

The two opposing surfaces of each slice were analysed microscopically. A light microscope, at a magnification

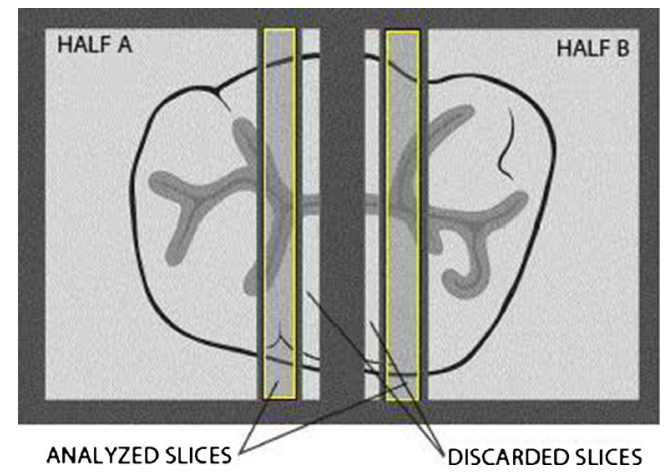

Fig. 1 Buccolingual sectioning produced two slices from each half tooth $(A, B)$. Analysis was performed on the second slice only, the first one being discarded

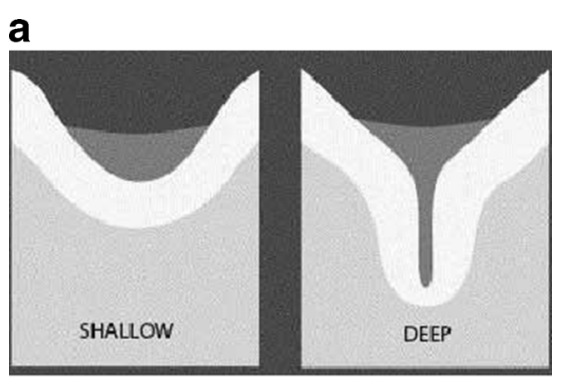

b

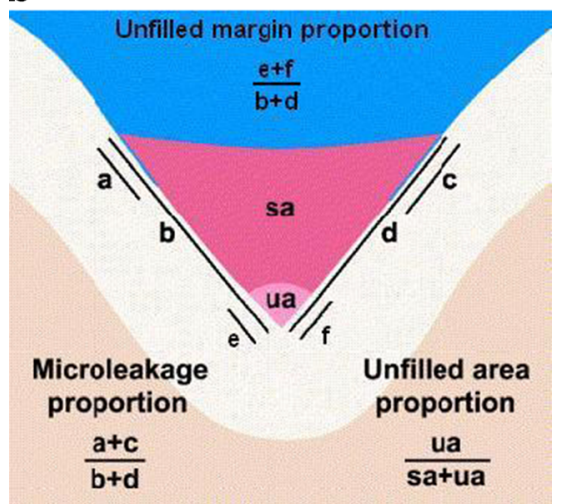

Fig. 2 a The fissures were classified into shallow and deep fissures. b Definition of the various proportions calculated for each fissure sealant. $a$ and $c$ microleakage, $b$ and $d$ sealant interface, $e$ and $f$ unfilled sealant interface, $u a$ unfilled area, $s a$ total fissure sealant area

of $\times 16-35$ (Leica M420, Leica, Heerbrugg, Switzerland), was used to photograph the fissure. The length of dye penetration (micrometres), the total length of enamel-sealant interface (micrometres), the length of unfilled enamel-sealant interface (micrometres), the total fissure area (square micrometres) and the unfilled area (voids) (square micrometres) were measured on each photograph using specialized software (Leica IM500, Leica, Heerbrugg, Switzerland). Some proportions were calculated as seen in Fig. $2 b$ and further explained below. The microleakage proportion was calculated by dividing the length of dye penetration (micrometres) $(\mathrm{a}+\mathrm{c})$ with the total length of the enamel-sealant interface (micrometres) $(b+d)$. The total length of the enamel-sealant interface (micrometres) was defined as the length of the enamel covered by the fissure sealant $(b+d)$. The unfilled margin proportion was calculated by dividing the length of unfilled enamel-sealant interface (micrometres) $(\mathrm{e}+\mathrm{f})$ with the total length of the enamelsealant interface (micrometres) $(b+d)$. The length of dye penetration (micrometres) $(\mathrm{a}+\mathrm{c})$ and the length of unfilled enamel-sealant interface (micrometres) $(e+f)$ were added and divided by the total enamel-sealant interface (micrometres) to arrive at the sealant failure proportion. Finally, the unfilled area (square micrometres) (ua) was divided by the total fissure area (square micrometres) (sa) to give the unfilled area proportion. The total fissure area (square micrometres) was defined as the whole surface of fissure sealant (sa). Mean values of the two opposing 
surfaces from each slice were calculated and used for the statistical analysis.

Descriptive statistics were obtained with R 2.9.1 software (The R Foundation for Statistical Computing, Vienna, Austria; www.r-project.org). A nonparametric ANOVA model was applied to compare the Er:YAG treatment with that of air-abrasion and the self-etch adhesive with phosphoric acid with regard to microleakage proportion, unfilled margin proportion, sealant failure proportion and unfilled area proportion $(\alpha=0.05)$. To see if the test groups differed from the control group, Wilcoxon rank sum tests were used $(\alpha=0.05)$. A Chi-squared test was applied to compare the distribution of the two fissure types in the five groups. The data of preliminary tests had been statistically analysed for sample size determination after the level of significance had been set at $\alpha=0.05$.

\section{Results}

The results are shown in Table 1 and in Fig. 3a-d. As a general finding, all sealants in test groups 1 (air abrasion) and 2 (laser) displayed microleakage, whereas the control group displayed nearly no microleakage as only one sample had dye penetration. However, all groups displayed unfilled margins, sealant failure and unfilled areas. There was no statistical difference between Er:YAG laser treatment and air-abrasion treatment for any of the outcome parameters. There were also no statistical differences between $\mathrm{H}_{3} \mathrm{PO}_{4}$ etching and self-etch adhesive for any of the parameters or any statistically significant interactions. Of the 100 slices analysed (two slices for every tooth half: A and B, and four slices for each control group tooth), 61 were classified as shallow fissures and 39 as deep fissures. There was no significant difference between the distribution of the two fissure types in the five groups $(P=0.9642)$.

Statistically significant differences were observed between the test groups and the control group for some of the outcome parameters (Table 2). There was a significant difference between the laser + self-etch adhesive group and the control group as regards the microleakage proportion and the unfilled area proportion. The control group displayed lower values for the microleakage proportion but higher values for the unfilled area proportion. There was also a significant difference between the air-abrasion + selfetch adhesive group and the control group as regards the unfilled margin proportion and the unfilled area proportion. The control group showed worse results than did the air-
Table 1 Microleakage, unfilled margin, sealant failure and unfilled area of the different treatment methods

\begin{tabular}{|c|c|c|c|c|}
\hline & First quartile & Median & Third quartile & Range \\
\hline \multicolumn{5}{|l|}{ Microleakage proportion } \\
\hline Air-abrasion $+\mathrm{H}_{3} \mathrm{PO}_{4}$ & 0.00 & 0.00 & 0.00 & $0-100$ \\
\hline Air-abrasion + self-etch adhesive & 0.00 & 0.00 & 2.94 & $0-11.39$ \\
\hline Laser $+\mathrm{H}_{3} \mathrm{PO}_{4}$ & 0.00 & 3.38 & 15.65 & $0-100$ \\
\hline Laser + self-etch adhesive & 0.00 & 2.84 & 7.87 & $0-9.18$ \\
\hline $\mathrm{H}_{3} \mathrm{PO}_{4}$ (control) & 0.00 & 0.00 & 0.00 & $0-0.01$ \\
\hline \multicolumn{5}{|l|}{ Unfilled margin proportion } \\
\hline Air-abrasion $+\mathrm{H}_{3} \mathrm{PO}_{4}$ & 0.00 & 7.54 & 26.37 & $0-100$ \\
\hline Air-abrasion + self-etch adhesive & 0.00 & 0.00 & 9.33 & $0-10.30$ \\
\hline Laser $+\mathrm{H}_{3} \mathrm{PO}_{4}$ & 0.00 & 4.43 & 23.95 & $0-100$ \\
\hline Laser + self-etch adhesive & 0.00 & 5.03 & 16.69 & $0-30.97$ \\
\hline $\mathrm{H}_{3} \mathrm{PO}_{4}$ (control) & 0.02 & 4.63 & 23.98 & $0-36.07$ \\
\hline \multicolumn{5}{|l|}{ Sealant failure proportion } \\
\hline Air-abrasion $+\mathrm{H}_{3} \mathrm{PO}_{4}$ & 1.23 & 7.81 & 26.37 & $0-100$ \\
\hline Air-abrasion + Self-etch adhesive & 0.00 & 6.58 & 10.06 & 16.25 \\
\hline Laser $+\mathrm{H}_{3} \mathrm{PO}_{4}$ & 2.39 & 15.36 & 24.59 & $0-100$ \\
\hline Laser + self-etch adhesive & 0.00 & 12.72 & 23.06 & $0-32.68$ \\
\hline $\mathrm{H}_{3} \mathrm{PO}_{4}$ (control) & 0.02 & 4.63 & 23.98 & $0-36.07$ \\
\hline \multicolumn{5}{|l|}{ Unfilled area proportion } \\
\hline Air-abrasion $+\mathrm{H}_{3} \mathrm{PO}_{4}$ & 0.00 & 1.12 & 4.10 & $0-100$ \\
\hline Air-abrasion + self-etch adhesive & 0.00 & 0.58 & 1.69 & $0-2.29$ \\
\hline Laser $+\mathrm{H}_{3} \mathrm{PO}_{4}$ & 0.00 & 0.61 & 4.73 & $0-100$ \\
\hline Laser + self-etch adhesive & 0.00 & 0.00 & 0.91 & $0-16.58$ \\
\hline $\mathrm{H}_{3} \mathrm{PO}_{4}$ (control) & 0.09 & 1.08 & 5.16 & $0-11.30$ \\
\hline
\end{tabular}


a

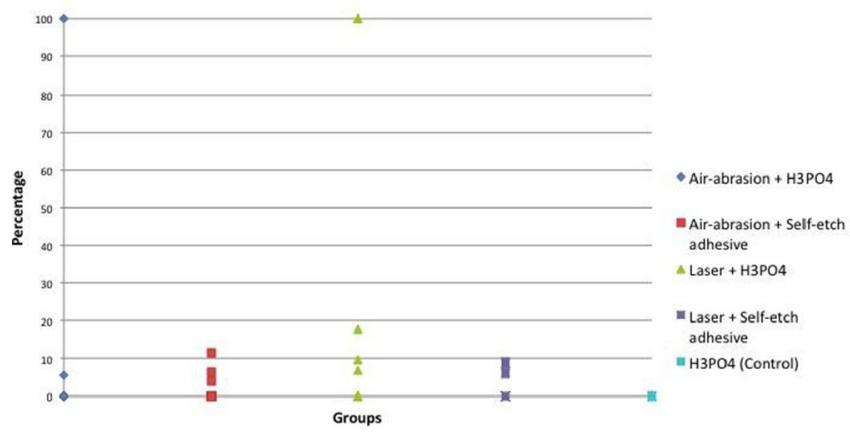

b

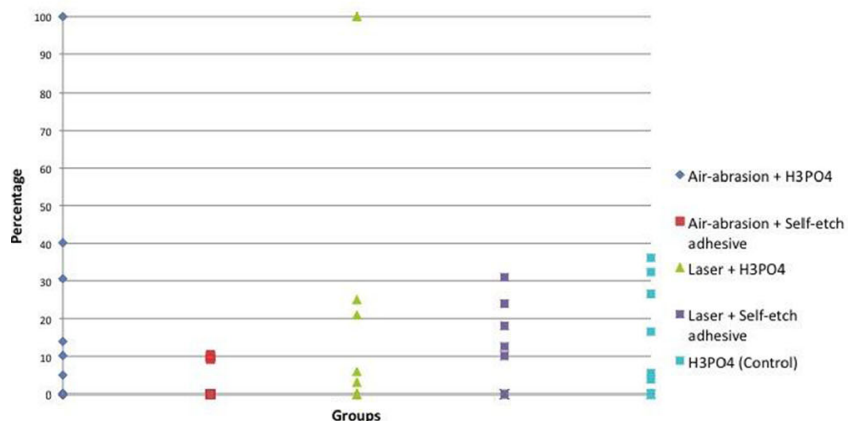

Fig. 3 a The microleakage proportion for each of the slices in the five treatment groups. b The unfilled margin proportion for each of the slices in the five treatment groups. c The sealant failure

abrasion + self-etch adhesive group regarding both outcome parameters.

Representative photographs of the sealed fissures are shown in Fig. 4a-e. Er:YAG laser treatment was found to result in white and rough edges, whereas air abrasion created a smoother surface. The powder used by the air-abrasion technique proved difficult to remove even by thorough rinsing and powder particles appeared as white residues at the bottom of the fissures.

\section{Discussion}

According to modern theories on caries and its treatment, the early detection of caries enhances the possibility of remineralisation and minimizes loss of dental hard tissue [20]. This is mainly obtained by allowing the dentist to take either preventive or minimally invasive measures. Fissure
C

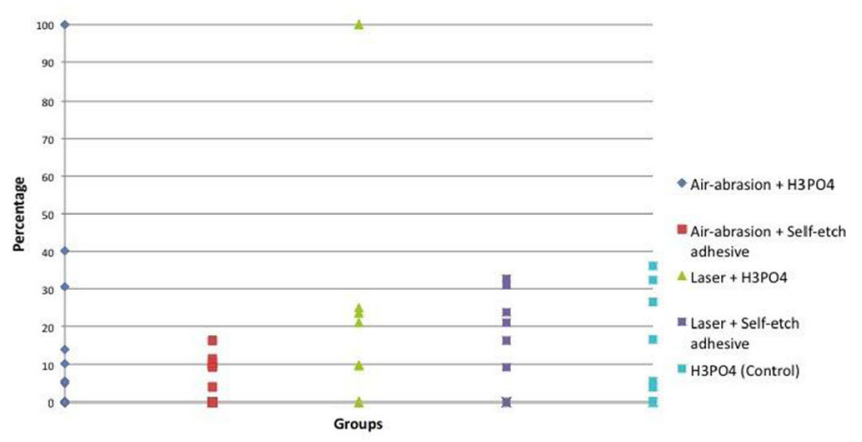

d Unfilled area proportion

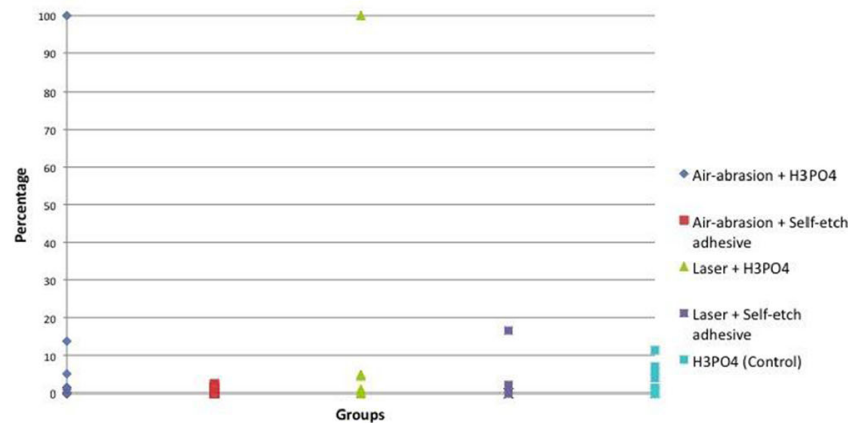

proportion for each of the slices in the five treatment groups. d The unfilled area proportion for each of the slices in the five treatment groups

sealants can be viewed as both a method of prophylactic and minimal invasive dentistry as they not only serve as mechanical barriers against plaque but also can be used to seal initial carious lesions of the occlusal surface [21]. Although sealants are often placed on enamel caries [4], in the present study, only enamel surfaces without caries were used so as to avoid any uncontrollable effect that an alteration of the enamel surface caused by an initial caries process might have on the wetting and adaptation of the sealant.

Retention of a fissure sealant is due to the microscopic porosities created in enamel after surface preparation or conditioning. These porosities increase the enamel surface area in contact with the sealant as well as the wettability and the spread and penetration of the resin. It has been shown that the depth of this penetration confers sealant micromechanical retention to enamel [22]. Several microleakage studies have shown that enamel conditioning by phosphoric acid etching
Table 2 Statistical comparison ( $P$ values) between the test groups and the control group for the various outcome parameters

$N S$ not significant

${ }^{a}$ Indicates a statistically significant difference $(\alpha=0.05)$

\begin{tabular}{lllll}
\hline & Microleakage & Unfilled margin & Sealant failure & Unfilled area \\
\hline Laser $+\mathrm{H}_{3} \mathrm{PO}_{4}$ vs control & $\mathrm{NS}$ & $\mathrm{NS}$ & $\mathrm{NS}$ & $\mathrm{NS}$ \\
Laser + self-etch adhesive vs control & $0.040^{\mathrm{a}}$ & $\mathrm{NS}$ & $\mathrm{NS}$ & $0.029^{\mathrm{a}}$ \\
Air-abrasion $+\mathrm{H}_{3} \mathrm{PO}_{4}$ vs control & $\mathrm{NS}$ & $\mathrm{NS}$ & $\mathrm{NS}$ & $\mathrm{NS}$ \\
Air-abrasion + self-etch adhesive vs control & $\mathrm{NS}$ & $0.014^{\mathrm{a}}$ & $\mathrm{NS}$ & $0.028^{\mathrm{a}}$ \\
\hline
\end{tabular}


a

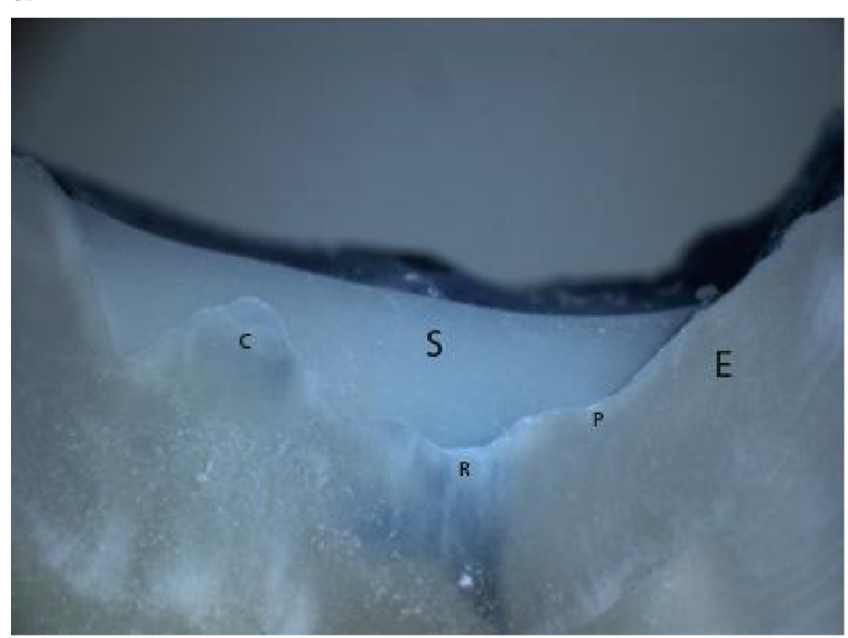

b

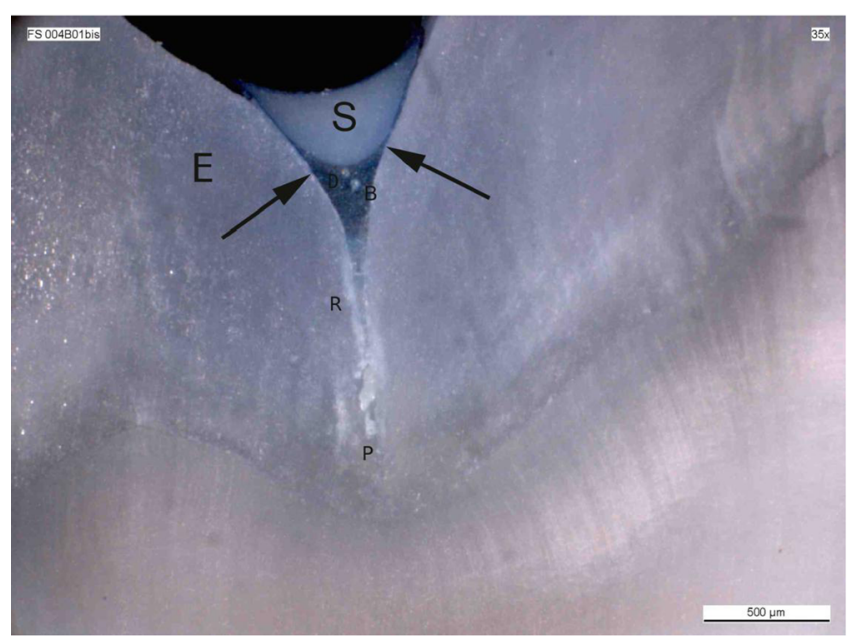

C

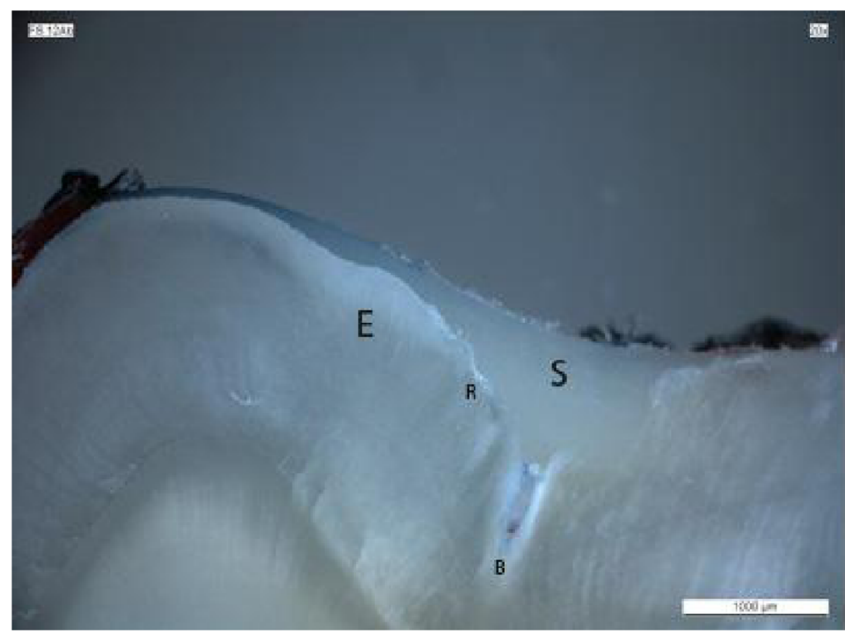

d

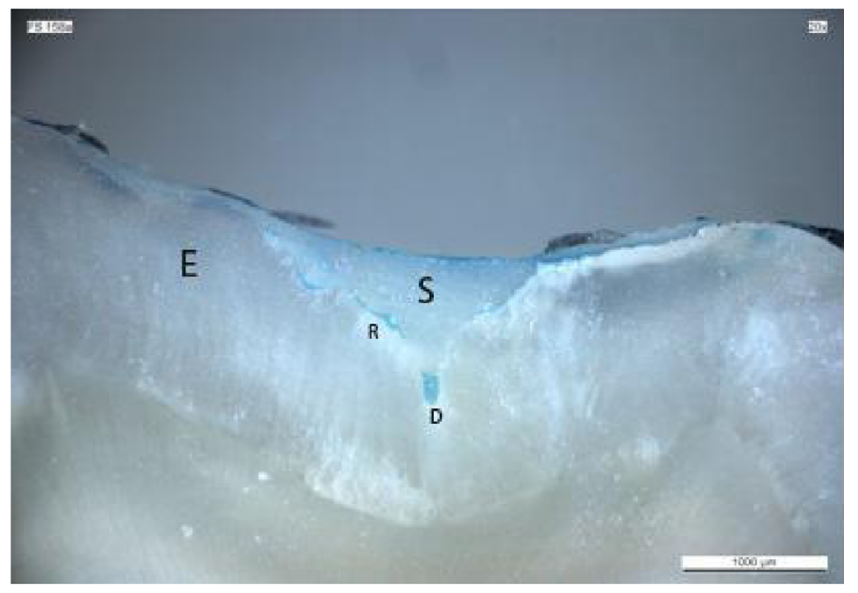

e

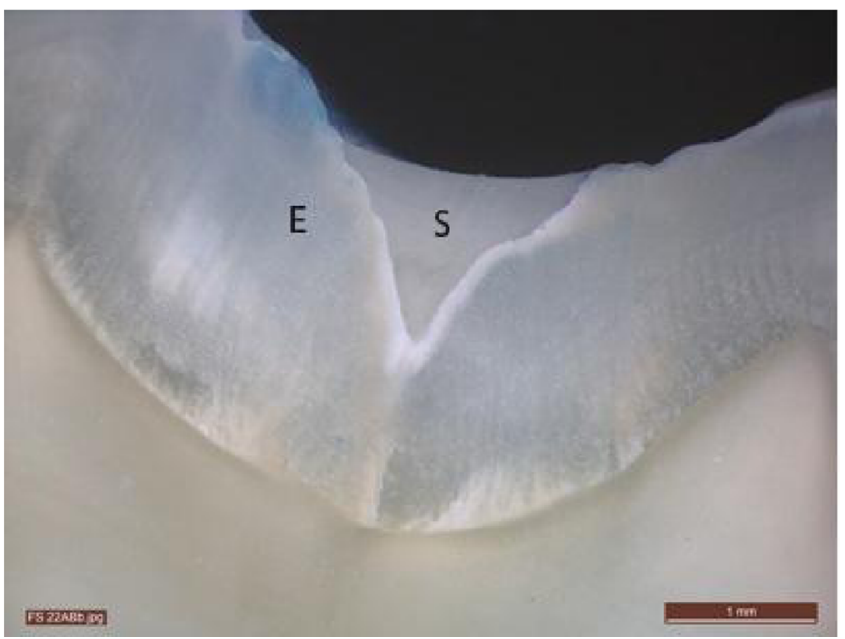

alone is superior to enamel conditioning by laser or airabrasion treatment $[23,24]$. However, contrasting results have been found when phosphoric acid etching was used in adjunction with laser or air-abrasion treatment $[23,25]$. The findings of the present study indicate that not only did pre-treatment of enamel with Er:YAG laser or air abrasion produce comparable microleakage results but these two treatments coupled with either phosphoric acid etching or a self-etch adhesive also 
Fig. 4 a Fissure treated with air abrasion and $\mathrm{H}_{3} \mathrm{PO}_{4}$ etching prior to application of sealant $(S)$. Remnants of air-abrasion powder $\left(\mathrm{Al}_{2} \mathrm{O}_{3}\right)$ are visible as white residue $(P)$. Air abrasion roughened the surface as seen by the whitish appearance of the enamel $(R)$. The fissure is separated by a small "cusp" $(C)$ which, before treatment, was probably higher and divided the fissure in two. This cusp was air-abraded turning the two initial fissures into a single one. Enamel $(E)$. b Fissure treated with airabrasion and self-etch adhesive prior to application of sealant $(S)$. As in a, the air-abrasion powder $\left(\mathrm{Al}_{2} \mathrm{O}_{3}\right)$ caused a white residue at the bottom of the fissure $(P)$. The self-etch adhesive layer at the bottom of the fissure was stained by the dye $(D)$. There was pooling of the self-etch adhesive and presence of microleakage. Two air bubbles $(B)$ can be observed creating unfilled areas and unfilled margins. Enamel $(E)$. Two arrows indicate the depth to which microleakage has occurred. $\mathbf{c}$ Fissure treated with Er:YAG laser and $\mathrm{H}_{3} \mathrm{PO}_{4}$ etching prior to application of sealant $(S)$. The white and rough edges are characteristic of laser treatment $(R)$ compared to the more smooth surface created after the use of air abrasion. An air bubble $(B)$ had formed at the bottom of the fissure where the sealant has not been able to create a tight seal. Enamel $(E)$. d Fissure treated with Er:YAG laser and self-etch adhesive prior to application of sealant $(S)$. The white and rough edges after the laser treatment can be seen $(R)$. The adhesive has been stained blue by the dye $(D)$. There was a pooling of the self-etch adhesive. The right hand part of the fissure is slightly darker due to the crack present in the sealant and the staining is seen up to the enamel-sealant interface. Enamel $(E)$. e Fissure sealant of the phosphoric acid etched control group. The $\mathrm{V}$-shaped fissure has been completely filled with sealant $(S)$, and there is no dye penetration at the enamel-sealant interface. Enamel $(E)$

generally performed similar to that of the phosphoric acid etching control group.

Nevertheless, Er:YAG laser treatment and air-abrasion treatments are both coupled with technical difficulties when used to prepare fissures. Laser treatment requires correct tip placement in order to deliver adequate energy to the enamel surface. It is difficult to angle the tip correctly in order to treat adequately all the area of the fissure walls as one has to follow the contours of the fissure system. A smaller tip can be used in order to be able to angle the tip more adequately; however, a smaller tip would make it more difficult to have a uniform treated surface. As the laser energy is delivered in a pulse mode, care has to be taken so that the entire enamel surface is treated and the laser tip has to be passed across the surface at a constant speed. The smaller the tip, the greater the time needed to compete the procedure, especially in the fissure system, as it is more difficult to visually check the enamel surface. Furthermore, as the tip is small, more energy is dispersed than a larger tip and may result in overablative energies if the tip is kept in the same area for too long. This may result in flaking of enamel and the appearance of white and rough edges. Sub-ablative energies may result in incomplete etching of the enamel surface and enamel heating and vitrification. In the case of air abrasion, the jet has to be correctly angulated in order to deliver the adequate amount of energy and powder. Furthermore, the powder projected and accumulated inside the fissure system may cause disturbances and hinder the further performance of the air-abrasion technique on the fissure system.
The adjunction of phosphoric acid etching to laser or airabrasion pre-treated enamel, in the present study, did not surpass simple acid etching. This finding corroborates previous findings [25-27] and could be explained by the fact that the macroscopically increased surface roughness by laser and/or air abrasion does not permit increased sealant retention of the sealant as it forms an irregular etching pattern that differs from that of conventional acid etching due to the previously discussed technical difficulties. Lasertreated fissures, as reported in the results, displayed white and rough edges. The lifting off and removal of the surface layer can explain these edges. Over-ablation could have caused these marks. Furthermore, in the case of subablative energies, enamel vitrification may result due to the change of the properties of heated enamel [28]. It has also been found that micro-cracks may result after laser treatment [29]. All these different effects may influence the conditioning effect [30] and thus, in some areas, the quality of the marginal seal.

Self-etch adhesives have been found to promote significantly lower bond strengths to intact enamel than to ground enamel [31]. However, previous studies have not shown the use of a self-etch adhesive instead of phosphoric acid etching before the application of a sealant to increase microleakage around the sealant $[32,33]$. Our results corroborate this finding in that the self-etch adhesive applied after laser treatment or after air abrasion performed similarly to the phosphoric acid etching control group with regard to microleakage.

Dye penetration is a commonly used test. Nevertheless, dye penetration as a means of quantifying microleakage has been criticized of not being a standardized test as it is known to be sensitive to methodology parameters (e.g. type of dye, immersion medium, immersion time, thermo-cycling and/or mechanical loading conditions) and of lacking reproducibility and clinical relevance [34-38]. This critique should be borne in mind when evaluating the present results.

Fissure morphology may influence the application and retention of sealants. Shallow fissures tended to show less unfilled areas than deep fissures probably because sealant penetration and adaptation are easier to obtain when the fissure angles are wide and concords with previous studies [39]. It is also probably easier for the clinician to eliminate trapped air bubbles from shallow fissures than from deep fissures, the dental probe or brush being able to descend right to the bottom of the fissure system in shallow fissures to dislodge the air pockets. The use of the self-etch adhesive before application of the sealant but after either laser or airabrasion treatment reduced the amount of unfilled area and unfilled margins compared to the phosphoric acid-etch control group. This is probably due to superior wetting properties of the unfilled adhesive as compared to the filled sealant, allowing more complete penetration and adaptation. As visualized by light blue coloration (Fig. 4b, d), the self-etch 
adhesive tended to pool in the deepest, very narrow parts of deep fissures despite an effort to distribute it across the surface with a soft jet of air. It can be seen that the whole body of the adhesive is lightly coloured. Figure $4 \mathrm{~b}$ arrows indicate the depth to which microleakage has occurred. It can be noted that in the case of microleakage, there is a slight colouring of the enamel. Further down the enamelsealant interface, enamel colouring is absent. Furthermore, one can see that, in Fig. 4d, there is no trace of microleakage between the enamel-self-adhesive interfaces; it therefore can be concluded that the adhesive layer was dyed during the preparation of the samples.

The economic aspect of placing a sealant has to be taken into account [40]. Sealant application has to remain simple and rapid and affordable in order to be used as prophylactic measures. Even if laser or air-abrasion treatment followed by application of a self-etch adhesive improved the adaptation of the fissure sealants as compared to application of only phosphoric acid etching, considering the extra time and cost of equipment and material required, the cost-benefit gain would seem questionable.

Based on an overall evaluation of all outcome parameters determined in this in vitro study, it is concluded that traditional phosphoric acid etching remains the most effective method to condition fissures prior to application of a sealant. Further research should be undertaken to evaluate the effects of enamel conditioning on sealant retention in vivo.

Acknowledgments The authors would like to thank S. Hayoz and Prof. Dr. J. Hüsler, Institute of Mathematical Statistics and Actuarial Science, University of Bern for statistical analyses.

\section{References}

1. Menghini G, Steiner M, Thomet E, Rath C, Marthaler T, Imfeld T (2010) Further caries decline in Swiss recruits from 1996 to 2006. Schweiz Monatsschr Zahnmed 120(7):590-595

2. Attrill DC, Ashley PF (2001) Occlusal caries detection in primary teeth: a comparison of DIAGNOdent with conventional methods. Br Dent J 190(8):440-443

3. Gooch BF, Griffin SO, Gray SK, Kohn WG, Rozier RG, Siegal M, Fontana M, Brunson D, Carter N, Curtis DK, Donly KJ, Haering H, Hill LF, Hinson HP, Kumar J, Lampiris L, Mallatt M, Meyer DM, Miller WR, Sanzi-Schaedel SM, Simonsen R, Truman BI, Zero DT (2009) Preventing dental caries through school-based sealant programs: updated recommendations and reviews of evidence. J Am Dent Assoc 140(11):1356-1365

4. Splieth CH, Ekstrand KR, Alkilzy M, Clarkson J, Meyer-Lueckel H, Martignon S, Paris S, Pitts NB, Ricketts DN, van Loveren C (2010) Sealants in dentistry: outcomes of the ORCA Saturday Afternoon Symposium 2007. Caries Res 44(1):3-13

5. Braga MM, Martignon S, Ekstrand KR, Ricketts DN, Imparato JC, Mendes FM (2010) Parameters associated with active caries lesions assessed by two different visual scoring systems on occlusal surfaces of primary molars - a multilevel approach. Community Dent Oral Epidemiol 38(6):549-558
6. Ekstrand KR, Ricketts DN, Kidd EA (2001) Occlusal caries: pathology, diagnosis and logical management. Dent Update 28(8):380-387

7. Ricketts D, Kidd E, Weerheijm K, de Soet H (1997) Hidden caries: what is it? Does it exist? Does it matter? Int Dent J 47(5):259-265

8. Chu CH, Lo EC, You DS (2010) Clinical diagnosis of fissure caries with conventional and laser-induced fluorescence techniques. Lasers Med Sci 25(3):355-362

9. Hormati AA, Fuller JL, Denehy GE (1980) Effects of contamination and mechanical disturbance on the quality of acid-etched enamel. J Am Dent Assoc 100(1):34-38

10. Celiberti P, Lussi A (2005) Use of a self-etching adhesive on previously etched intact enamel and its effect on sealant microleakage and tag formation. J Dent 33(2):163-171

11. Hebling J, Feigal RJ (2000) Use of one-bottle adhesive as an intermediate bonding layer to reduce sealant microleakage on saliva-contaminated enamel. Am J Dent 13(4):187-191

12. Peumans M, Kanumilli P, De Munck J, Van Landuyt K, Lambrechts P, Van Meerbeek B (2005) Clinical effectiveness of contemporary adhesives: a systematic review of current clinical trials. Dent Mater 21(9):864-881

13. Erickson RL, Barkmeier WW, Kimmes NS (2009) Bond strength of self-etch adhesives to pre-etched enamel. Dent Mater 25(10): 1187-1194

14. Bader C, Krejci I (2006) Indications and limitations of Er:YAG laser applications in dentistry. Am J Dent 19(3):178-186

15. Hibst R, Keller U (1989) Experimental studies of the application of the Er:YAG laser on dental hard substances: I. Measurement of the ablation rate. Lasers Surg Med 9(4):338-344

16. Christensen GJ (1998) Air abrasion tooth cutting: state of the art 1998. J Am Dent Assoc 129(4):484-485

17. Neuhaus KW, Ciucchi P, Donnet M, Lussi A (2010) Removal of enamel caries with an air abrasion powder. Oper Dent 35(5):538-546

18. Goldstein RE, Parkins FM (1995) Using air-abrasive technology to diagnose and restore pit and fissure caries. J Am Dent Assoc 126(6):761-766

19. Zero DT, Rahbek I, Fu J, Proskin HM, Featherstone JD (1990) Comparison of the iodide permeability test, the surface microhardness test, and mineral dissolution of bovine enamel following acid challenge. Caries Res 24(3):181-188

20. Murdoch-Kinch CA, McLean ME (2003) Minimally invasive dentistry. J Am Dent Assoc 134(1):87-95

21. Waggoner WF, Siegal M (1996) Pit and fissure sealant application: updating the technique. J Am Dent Assoc 127(3):351-361, quiz 391-352

22. Gwinnett AJ, Matsui A (1967) A study of enamel adhesives. The physical relationship between enamel and adhesive. Arch Oral Biol 12(12):1615-1620

23. Baygin O, Korkmaz FM, Tuzuner T, Tanriver M (2012) The effect of different enamel surface treatments on the microleakage of fissure sealants. Lasers Med Sci 27(1):153-160

24. Borsatto MC, Corona SA, Ramos RP, Liporaci JL, Pecora JD, Palma-Dibb RG (2004) Microleakage at sealant/enamel interface of primary teeth: effect of Er:YAG laser ablation of pits and fissures. J Dent Child (Chic) 71(2):143-147

25. Borsatto MC, Corona SA, Dibb RG, Ramos RP, Pecora JD (2001) Microleakage of a resin sealant after acid-etching, Er:YAG laser irradiation and air-abrasion of pits and fissures. J Clin Laser Med Surg 19(2):83-87

26. Lupi-Pegurier L, Muller-Bolla M, Bertrand MF, Fradet T, Bolla M (2004) Microleakage of a pit-and-fissure sealant: effect of airabrasion compared with classical enamel preparations. J Adhes Dent 6(1):43-48

27. Manhart J, Huth KC, Chen HY, Hickel R (2004) Influence of the pretreatment of occlusal pits and fissures on the retention of a fissure sealant. Am J Dent 17(1):12-18 
28. Delme KI, De Moor RJ (2007) Scanning electron microscopic evaluation of enamel and dentin surfaces after Er:YAG laser preparation and laser conditioning. Photomed Laser Surg 25(5):393-401

29. Rodriguez-Vilchis LE, Contreras-Bulnes R, Sanchez-Flores I, Samano EC (2010) Acid resistance and structural changes of human dental enamel treated with Er:YAG laser. Photomed Laser Surg 28(2):207-211

30. Frentzen M, Winkelstrater C, van Benthem H, Koort HJ (1996) The effects of pulsed ultraviolet and infra-red lasers on dental enamel. Eur J Prosthodont Restor Dent 4(3):99-104

31. Osorio R, Monticelli F, Moreira MA, Osorio E, Toledano M (2009) Enamel-resin bond durability of self-etch and etch \& rinse adhesives. Am J Dent 22(6):371-375

32. Cehreli ZC, Gungor HC (2008) Quantitative microleakage evaluation of fissure sealants applied with or without a bonding agent: results after four-year water storage in vitro. J Adhes Dent 10(5):379-384

33. Marks D, Owens BM, Johnson WW (2009) Effect of adhesive agent and fissure morphology on the in vitro microleakage and penetrability of pit and fissure sealants. Quintessence Int 40(9):763-772
34. de Almeida JB, Platt JA, Oshida Y, Moore BK, Cochran MA, Eckert GJ (2003) Three different methods to evaluate microleakage of packable composites in Class II restorations. Oper Dent 28(4):453-460

35. Heintze S, Forjanic M, Cavalleri A (2008) Microleakage of Class II restorations with different tracers - comparison with SEM quantitative analysis. J Adhes Dent 10(4):259-267

36. Heintze SD (2007) Systematic reviews: I. The correlation between laboratory tests on marginal quality and bond strength. II. The correlation between marginal quality and clinical outcome. $\mathrm{J}$ Adhes Dent 9(Suppl 1):77-106

37. Raskin A, D'Hoore W, Gonthier S, Degrange M, Dejou J (2001) Reliability of in vitro microleakage tests: a literature review. J Adhes Dent 3(4):295-308

38. Raskin A, Tassery H, D'Hoore W, Gonthier S, Vreven J, Degrange M, Dejou J (2003) Influence of the number of sections on reliability of in vitro microleakage evaluations. Am J Dent 16(3):207-210

39. Sutalo J, Pupic V, Velenje T, Ciglar I, Skaljac G, Tuda M (1989) Scanning electron microscopic study of penetrability of sealants in relation to fissure morphology of permanent premolars in humans. Oralprophylaxe 11(3):83-88

40. Kitchens DH (2005) The economics of pit and fissure sealants in preventive dentistry: a review. J Contemp Dent Pract 6(3):95-103 